\title{
Dipeptidyl peptidase-4 inhibitors in type 2 diabetes therapy - focus on alogliptin
}

This article was published in the following Dove Press journal:

Drug Design, Development and Therapy

19 September 2013

Number of times this article has been viewed

\author{
Annalisa Capuano' \\ Liberata Sportiello' \\ Maria Ida Maiorino ${ }^{2}$ \\ Francesco Rossi' \\ Dario Giugliano ${ }^{2}$ \\ Katherine Esposito 3 \\ 'Department of Experimental \\ Medicine, ${ }^{2}$ Department of Medical, \\ Surgical, Neurological, Metabolic \\ Sciences, and Geriatrics, ${ }^{3}$ Department \\ of Clinical and Experimental Medicine \\ and Surgery, Second University \\ of Naples, Naples, Italy
}

Correspondence: Dario Giugliano Department of Medical, Surgical, Neurological, Metabolic Sciences, and Geriatrics, University Hospital at the Second University of Naples, Piazza L Miraglia 2, 80138 Naples, Italy $\mathrm{Tel} / \mathrm{Fax}+3908 \mathrm{I} 5665054$

Email dario.giugliano@unina2.it
Abstract: Type 2 diabetes mellitus is a complex and progressive disease that is showing an apparently unstoppable increase worldwide. Although there is general agreement on the first-line use of metformin in most patients with type 2 diabetes, the ideal drug sequence after metformin failure is an area of increasing uncertainty. New treatment strategies target pancreatic islet dysfunction, in particular gut-derived incretin hormones. Inhibition of the enzyme dipeptidyl peptidase-4 (DPP-4) slows degradation of endogenous glucagon-like peptide-1 (GLP-1) and thereby enhances and prolongs the action of the endogenous incretin hormones. The five available DPP-4 inhibitors, also known as 'gliptins' (sitagliptin, vildagliptin, saxagliptin, linagliptin, alogliptin), are small molecules used orally with similar overall clinical efficacy and safety profiles in patients with type 2 diabetes. The main differences between the five gliptins on the market include: potency, target selectivity, oral bioavailability, long or short half-life, high or low binding to plasma proteins, metabolism, presence of active or inactive metabolites, excretion routes, dosage adjustment for renal and liver insufficiency, and potential drug-drug interactions. On average, treatment with gliptins is expected to produce a mean glycated hemoglobin $\left(\mathrm{HbA}_{1 \mathrm{c}}\right)$ decrease of $0.5 \%-0.8 \%$, with about $40 \%$ of diabetic subjects at target for the $\mathrm{HbA}_{1 \mathrm{c}}$ goal $<7 \%$. There are very few studies comparing DPP-4 inhibitors. Alogliptin as monotherapy or added to metformin, pioglitazone, glibenclamide, voglibose, or insulin therapy significantly improves glycemic control compared with placebo in adult or elderly patients with inadequately controlled type 2 diabetes. In the EXAMINE trial, alogliptin is being compared with placebo on cardiovascular outcomes in approximately 5,400 patients with type 2 diabetes. In clinical studies, DPP-4 inhibitors were generally safe and well tolerated. However, there are limited data on their tolerability, due to their relatively recent marketing approval. Alogliptin will be used most when avoidance of hypoglycemic events is paramount, such as in patients with congestive heart failure, renal failure, and liver disease, and in the elderly.

Keywords: type 2 diabetes, DPP-4 inhibitors, alogliptin

\section{Introduction}

In 2011, there were 366 million people with diabetes worldwide, and this is expected to rise to 552 million by 2030 , rendering previous estimates very conservative. ${ }^{1}$ Excluding accidents, diabetes is the fifth cause of death for women and the fourth for men in the USA. ${ }^{2}$ Tight glycemic control, to maintain a hemoglobin A1c $\left(\mathrm{HbA}_{1 \mathrm{c}}\right)$ concentration of $7 \%$ or lower, is recommended for many nonpregnant adults with diabetes to minimize the risk of long-term vascular complications. ${ }^{3}$ As a consequence, current diabetes guidelines ${ }^{4}$ suggest adjustment of therapy based on $\mathrm{HbA}_{1 \mathrm{c}}$ level. However, there is little evidence about the relative effects of various antihyperglycemic therapies on clinical outcomes, 
with the possible exception of metformin, which appears moderately protective on cardiovascular $(\mathrm{CV})$ outcomes. ${ }^{5}$

Although there is general agreement on the first-line use of metformin in most patients with type 2 diabetes, the ideal drug sequence after metformin failure is an area of increasing uncertainty, ${ }^{6}$ given the panoply of diabetes medications so far available for treatment of hyperglycemia. There are 45 rational and US Food and Drug Administrationpermissible combinations that can be used in dual therapy. ${ }^{7}$ A recent estimate claims 150 therapeutic options for triple therapy and 600 options for quadruple therapy, not including the different options within each class, for example, basal vs premixed insulin. ${ }^{8}$

The failure to achieve glycemic goals in a large portion of this population is, in part, due to limitations in the current treatment options available to patients with type 2 diabetes. Many oral diabetes medications are associated with side effects that limit their use, including hypoglycemia (sulfonylureas, insulin, meglitinides), weight gain (sulfonylureas, thiazolidinediones, insulin), gastrointestinal side effects (metformin, exenatide, $\alpha$-glucosidase inhibitors), and fluid retention (thiazolidinediones and insulin). Even if these medications are initially effective, glycemic control gradually worsens over time in most patients owing to a steady and progressive decline in pancreatic $\beta$-cell function. There is at present no robust evidence that a single therapeutic agent can address all pathogenetic factors associated with the progressive exhaustion of beta cells. As a corollary, most type 2 diabetic patients require more than one pharmacological option to achieve glycemic target. Ultimately, most patients will require insulin therapy. ${ }^{9}$

Antihyperglycemic agents also have the potential to contribute to therapeutic inertia, defined as the failure of health care providers to initiate or intensify therapy when indicated, ${ }^{10}$ via factors inherent to the drugs themselves, such as treatment-related adverse effects, perception of long-term safety profiles, and the complexity of the treatment regimen. Perhaps it is not by chance that the position statement from the American Diabetes Association/European Association for the Study of Diabetes (ADA/EASD) on the management of hyperglycemia in type 2 diabetes is subtitled 'a patientcentered approach'. ${ }^{4}$ This statement highlights the clinical judgment (a mixture of clinical experience, knowledge, and skill) of physicians together with the patients' values and preferences. However, physician feeling and conviction about the willingness to reach the $\mathrm{HbA}_{1 \mathrm{c}}$ target (now tailored on the patient) remain paramount to reduce unnecessary therapeutic inertia. ${ }^{11}$
An improved understanding of the pathogenesis of type 2 diabetes, including postprandial control of glucose homeostasis, has led to the emergence of new treatment strategies that target pancreatic islet dysfunction, in particular those that target gut-derived incretin hormones.

\section{The incretin system}

More than 20 years ago, Gutniak et al ${ }^{12}$ suggested that glucagonlike peptide-1 (GLP-1) might be a potential target in the treatment of type 2 diabetes, as they demonstrated that its intravenous infusion reduced the insulin requirement to meal ingestion in subjects with diabetes. At that time, it was already known that oral glucose ingestion elicited a greater insulin response than did intravenous glucose infusion, at the same level of attained glycemia. ${ }^{13}$ Later, this was called the incretin effect, and attributed to an increased glucose-stimulated insulin secretion induced by the gut incretin hormones released after glucose ingestion. ${ }^{14}$

The two incretin hormones with the greatest effect on glucose control are GLP-1 and glucose-dependent insulinotropic peptide (GIP). Both peptides are secreted within minutes of food consumption and act on pancreatic beta cells, through distinct receptors, to stimulate insulin secretion with dependency on blood glucose concentration; when glucose levels are normal, incretin-stimulated insulin secretion is suppressed. ${ }^{15}$ GLP-1 is a product of the proglucagon gene and is secreted from the L cells located in the distal gut into the capillaries and then into the blood stream. Activation of the GLP-1 receptors ( $G_{\alpha \mathrm{s}}$ protein-coupled receptors) expressed on the pancreatic $\beta$-cells elevates cAMP levels, which in turn activates protein kinase $\mathrm{A}$ and Epac 1 and 2, resulting in a glucose-dependent increase of insulin secretion by the $\beta$-cell. ${ }^{16} \mathrm{GLP}-1$ infusions have shown more promising results than those of GIP in lowering plasma glucose in diabetes. Other effects of GLP-1 include suppression of glucagon secretion, also exerted in a glucose-dependent manner, slowing of gastric emptying time, and promotion of satiety. The net effect of enhanced insulin secretion and suppressed glucagon secretion is decreased fasting and postprandial glucose levels. GLP-1 also increases $\beta$-cell mass through differentiation and proliferation of $\beta$-cells and inhibition of apoptosis, as shown in rodents. ${ }^{17}$ Since all of these effects are of potential value in the treatment of type 2 diabetes, GLP-1 has intensively been explored as a pharmacological therapy for the disease.

The incretin effect is greatly reduced in patients with type 2 diabetes - this plays an important contributory role in the insulin insufficiency and chronic hyperglycemia characteristic of the disease. ${ }^{18}$ The short half-life (1-2 minutes) of GLP-1 is a consequence of its rapid inactivation by the enzyme dipeptidyl 
peptidase-4 (DPP-4) that truncates the peptide by removal of the N-terminal dipeptide end. GLP-1 effects can be provided therapeutically by giving supplemental GLP-1 agonists, which are largely resistant to the action of DPP-4; the other approach is to inhibit the enzyme DPP-4, which slows degradation of endogenous GLP-1, and thereby enhances and prolongs the action of the endogenous incretin hormone.

\section{DPP-4 inhibitors: pharmacology, mode of action, pharmacokinetics}

DPP-4 (also known as lymphocyte cell surface protein CD26) is a membrane-spanning, cell-surface aminopeptidase ubiquitously expressed in many tissues, such as gut, lymphocyte, liver, kidney, lung, and endothelial cells. ${ }^{17}$ DPP-4 enzyme is a member of the DPP family, which also includes the structurally related enzymes DPP-2, DPP-8, DPP-9, and fibroblast activation protein; DPP-4 has several substrates, such as gastrointestinal hormones, neuropeptidase, cytokines, and chemokines. ${ }^{19}$

The five available DPP-4 inhibitors, also known as 'gliptins' (sitagliptin, vildagliptin, saxagliptin, linagliptin, alogliptin), are small molecules used orally with similar overall clinical efficacy and safety profiles in patients with type 2 diabetes. Sitagliptin was the first gliptin licensed by the US Food and Drug Administration (FDA) in 2006 (Table 1) and is now available worldwide; ${ }^{20}$ vildagliptin and saxagliptin were approved in 2007 and 2009, respectively. ${ }^{21,22}$ More recent compounds are alogliptin (available only in Japan in 2010) and linagliptin (authorized by the FDA and EU in 2011). ${ }^{23,24}$ DPP-4 inhibitors may be used as monotherapy or in double or triple combination with other oral glucose-lowering agents, as metformin, thiazolidinediones, or sulfonylureas. The authorized combined therapies in EU are reported in Table 2. Sitagliptin, vildagliptin, and saxagliptin are currently available as single agents or in a fixed-dose combination with metformin.

DPP-4 inhibitors reduce plasma DPP-4 activity by $70 \%$ $90 \%$ in a sustained manner for 24 hours with an increase of GLP-1 levels (1.5- to 4-fold). They do not pass the blood-brain barrier, have no direct central effect on satiety, and in contrast with GLP-1 agonists (incretin mimetics), did not alter gastric emptying. ${ }^{25}$ Although DPP-4 inhibitors have the same mode of action, they differ by some important pharmacokinetic and pharmacodynamic properties that may be clinically relevant in some patients. ${ }^{19}$ The main differences between the five gliptins on the market include: potency, target selectivity, oral bioavailability, long or short half-life, high or low binding to plasma proteins, metabolism, presence of active or inactive metabolites, excretion routes, dosage adjustment for renal and liver insufficiency, and potential drug-drug interactions (Table 3).
Table I DPP-4 inhibitors-based medicines authorized through central procedure by the European Medicines Agency (EMA)

\begin{tabular}{|c|c|c|}
\hline DPP-4 inhibitors & Medicines & $\begin{array}{l}\text { Date } \\
\text { of authorization }\end{array}$ \\
\hline \multirow[t]{4}{*}{ Sitagliptin } & Januvia ${ }^{\circledR}$ & $21 / 03 / 2007$ \\
\hline & Xelevia ${ }^{\circledR}$ & $21 / 03 / 2007$ \\
\hline & Tesavel $^{\circledR}$ & $10 / 01 / 2008$ \\
\hline & Ristaben $^{\circledast *}$ & $15 / 03 / 2010$ \\
\hline \multirow[t]{4}{*}{ Sitagliptin + metformin } & Efficib $^{\circledR}$ & $16 / 07 / 2008$ \\
\hline & Janumet ${ }^{\circledR}$ & $16 / 07 / 2008$ \\
\hline & Velmetia ${ }^{\circledR}$ & $16 / 07 / 2008$ \\
\hline & Ristfor $^{\circledR}$ & $15 / 03 / 2010$ \\
\hline \multirow[t]{3}{*}{ Vildagliptin } & Galvus ${ }^{\circledR}$ & $26 / 09 / 2007$ \\
\hline & Jalra ${ }^{\circledR *}$ & $19 / 11 / 2008$ \\
\hline & Xiliarx ${ }^{\circledR *}$ & $19 / 11 / 2008$ \\
\hline \multirow[t]{3}{*}{ Vildagliptin + metformin } & Eucreas $^{\circledR}$ & $14 / \mid 1 / 2007$ \\
\hline & Icandra $^{\circledR}$ & $01 / 12 / 2008$ \\
\hline & Zomarist $^{\circledR *}$ & $01 / 12 / 2008$ \\
\hline Saxagliptin & Onglyza ${ }^{\circledR}$ & $01 / 10 / 2009$ \\
\hline Saxagliptin + metformin & Komboglize ${ }^{\circledR}$ & $24 / 11 / 2011$ \\
\hline Linagliptin & Trajenta $^{\circledR} *$ & $24 / 08 / 2011$ \\
\hline Linagliptin + metformin & Jentadueto ${ }^{\circledR}$ & $20 / 07 / 2012$ \\
\hline
\end{tabular}

Note: *Not available in Italy. Data from European Medicines Agency [homepage on the Internet]. European public assessment reports (EPAR). [updated August, 20/3] Available from: http://www.ema.europa.eu/ema/index.jsp?curl=pages/medicines/ landing/epar search.jsp\&mid=WCOb0lac05800 IdI 24. Accessed August 29, 2013.72 Abbreviation: DPP, dipeptidyl peptidase.

\section{Pharmacodynamic properties}

Regarding potency, linagliptin, compared with sitagliptin, alogliptin, saxagliptin, and vildagliptin demonstrated the highest potency of DPP-4 inhibition ( $\mathrm{IC}_{50}$ values of $1 \mathrm{nM}$, $19 \mathrm{nM}, 24 \mathrm{nM}, 50 \mathrm{nM}$, and $62 \mathrm{nM}$, respectively). ${ }^{19,26,27}$ The duration of action of DPP-4 inhibitors with comparatively shorter half-lives may be strongly influenced by binding strength and reversibility with the receptor. ${ }^{28}$ All gliptins exhibit a greater selectivity for DPP-4 enzyme, ranging from 30- to 40,000-fold superior to the other enzymes, ie, DPP-8 and DPP-9. ${ }^{28,29}$ However, because DPP-8 and DPP-9 are proteases responsible for T-cell activation which play an important role in immune function, the off-target inhibition of selective DPP-4 inhibitors is responsible for toxicity (immune dysfunction, impaired healing, and skin reactions). ${ }^{29}$

\section{Pharmacokinetic properties}

After oral administration in humans, all DPP-4 inhibitors are well absorbed with oral bioavailability ranges 
Table 2 The combinations between DPP-4 inhibitors and other oral glucose-lowering agents authorized by the European Medicines Agency (EMA)

\begin{tabular}{|c|c|c|c|c|c|c|c|c|}
\hline Indications & Sitagliptin & Sita + Met & Vildagliptin & Vilda + Met & Saxagliptin & Saxa + Met & Linagliptin & Lina + Met \\
\hline Alone & Yes & Yes & Yes & Yes & - & Yes & Yes & Yes \\
\hline+ Met & Yes & - & Yes & - & Yes & - & Yes & - \\
\hline$+\mathrm{TZD}$ & Yes & Yes & Yes & - & Yes & - & - & - \\
\hline$+\mathrm{SU}$ & Yes & Yes & Yes & Yes & Yes & - & - & Yes \\
\hline+ Met and SU & Yes & - & Yes & - & - & - & Yes & - \\
\hline+ Met and TZD & Yes & - & - & - & - & - & - & - \\
\hline+ Insulin and \pm Met & Yes & Yes & Yes & Yes & Yes & Yes & - & - \\
\hline $\begin{array}{l}\text { Previous gliptin }+ \text { Met } \\
\text { (separately) }\end{array}$ & - & Yes & - & Yes & - & Yes & - & Yes \\
\hline $\begin{array}{l}\text { Dose adjustment } \\
\text { in kidney impairment }\end{array}$ & Yes & Yes & Yes & Yes & Yes & - & - & - \\
\hline
\end{tabular}

Abbreviations: DPP, dipeptidyl peptidase; Lina, linagliptin; Met, metformin; Saxa, saxagliptin; Sita, sitagliptin; Vilda, vildagliptin; SU, sulfonylurea; TZD, thiazolidinedione.

from approximately $30 \%$ with linagliptin to $75 \%-87 \%$ for all others and are not significantly influenced by food intake. ${ }^{30}$ Linagliptin has the longest half-life (120-184 hours), followed by alogliptin (12.4-21.4 hours), and sitagliptin (8-14 hours), whereas saxagliptin and vildagliptin have shorter half-lives (2.2-3.8 hours and $2-3$ hours, respectively). Due to a sustained DPP-4 enzyme inhibition and a long half-life, sitagliptin, alogliptin, and linagliptin are generally prescribed once a day. Saxagliptin is also administrated once daily due to the presence of an active metabolite (5-hydroxy saxagliptin) which is half as potent as the parent compound. Due to the shorter half-life, vildagliptin needs twice-daily dosing. ${ }^{31}$ The apparent volumes of distribution (Vd) among the gliptins range from 70 to $918 \mathrm{~L} .{ }^{25}$ Moreover, the distribution of DPP-4 inhibitors is strongly influenced by protein binding. All gliptins are not extensively bound to plasma proteins, except for linagliptin, which has the highest binding level to proteins. ${ }^{32}$

DPP-4 inhibitor metabolism is widely variable. While sitagliptin does not appear to undergo extensive metabolism, both vildagliptin and saxagliptin are extensively metabolized in the liver. However, vildagliptin produces a large amount of inactive metabolites through several pathways (hydrolysis, glucuronidation, and oxidation) not mediated by the cytochrome P450 (CYP) system, while saxagliptin is mainly metabolized by the CYP3A4/5 isoforms to a major active metabolite, 5-hydroxy saxagliptin (which is 2-fold less potent than its parent molecule). ${ }^{32-34}$ Both saxagliptin and its major metabolite are not inhibitors or inducers of various CYP isoforms. ${ }^{32}$ Although the potential for drug interactions with saxagliptin and its metabolite is low, their pharmacokinetic profile may be influenced in co-administration with strong CYP3A4/5 inducers (such as rifampicin) or inhibitors (such

Table 3 Main pharmacokinetic and pharmacodynamic properties of DPP-4 inhibitors available on the European market

\begin{tabular}{|c|c|c|c|c|c|}
\hline Parameters & Sitagliptin & Vildagliptin & Saxagliptin & Alogliptin & Linagliptin \\
\hline \multicolumn{6}{|l|}{ Pharmacodynamics } \\
\hline In vitro DPP-4 inhibition $\left(\mathrm{IC}_{50}\right.$ in $\left.\mathrm{nM}\right)$ & 19 & 62 & 50 & 24 & I \\
\hline DPP-4 selectivity (vs DPP-8 and DPP-9) & $>2,600$ & $<100$ & $<100$ & $>14,000$ & $>10,000$ \\
\hline \multicolumn{6}{|l|}{ Pharmacokinetics } \\
\hline Oral bioavailability (\%) & 87 & 85 & 75 & 70 & 30 \\
\hline Volume distribution (L) & 198 & 71 & $|5|$ & 300 & $368-918$ \\
\hline Fraction bound to proteins (\%) & 38 & 9.3 & $<10$ & 20 & 70 \\
\hline Half life $\left(T_{1 / 2}\right)(h)$ & $8-14$ & $2-3$ & $2.2-3.8$ & $|2.4-2| .4$ & $120-184$ \\
\hline Liver excretion (\%) & 13 & 4.5 & 22 & 13 & 85 \\
\hline Kidney excretion (\%) & 87 & 85 & 75 & 76 & 5 \\
\hline Proportion excreted unchanged (\%) & 79 & 23 & 24 & 95 & $\sim 90$ \\
\hline Substrate for CYP3A4/5 & Low & No & Yes & No & No \\
\hline Drug-drug interactions & Unknown & Unknown & $\begin{array}{l}\text { CYP3A4/5 inducers } \\
\text { and inhibitors }\end{array}$ & Unknown & Unknown \\
\hline
\end{tabular}

Note: Data were obtained from references 19, 25, 28, 29, 32.

Abbreviations: DPP, dipeptidyl peptidase; CYP, cytochrome P450. 
as ketoconazole); in these cases, it is recommended to modify the dosage of saxagliptin. ${ }^{34,35}$ The pharmacokinetic profiles of the other DPP-4 inhibitors suggest a low risk of drug-drug interactions, ${ }^{32}$ which is especially favorable in patients older than 65 years. $^{35}$

All DPP-4 inhibitors predominantly ( $75 \%-87 \%)$ undergo renal excretion, with $76 \%-87 \%$ of each dose eliminated as unchanged parent compound in the urine. In contrast, linagliptin is excreted mostly ( $\sim 90 \%)$ unchanged in feces via biliary excretion, ${ }^{19,25}$ and therefore appears to be safe in diabetic patients suffering from renal complications. ${ }^{29,34} \mathrm{An}$ appropriate dose reduction of the gliptins with predominantly renal excretion (sitagliptin, saxagliptin, and alogliptin, but not vildagliptin) is required in case of renal impairment. ${ }^{25,29,32}$ In patients with mild to severe liver impairment, no dose adjustment seems necessary for linagliptin despite its liver excretion. $^{25}$

\section{Efficacy studies}

In a meta-analysis of randomized controlled trials (RCTs) through September 2010, ${ }^{36}$ we assessed the effectiveness of different DPP-4 inhibitors to reach the recommended $\mathrm{HbA}_{1 \mathrm{c}}$ target of $<7 \%$ in people with type 2 diabetes. Of the 1,438 citations identified, we selected 43 studies, with 10,467 patients treated with a DPP-4 inhibitor. All studies were published between 2005 and 2010; all studies were of parallel groups, and most studies were of double- or triple-blind design. The duration of the studies ranged from 12-52 weeks, and most arms were of 24-26 weeks.

There were 14 RCTs testing vildagliptin, with 4,288 subjects. The direct random effect meta-analysis of RCTs showed that $37 \%$ of subjects achieved the $\mathrm{HbA}_{10}$ goal of $<7 \%$ at the end of treatment, without differences between the four arms in which vildagliptin was added to metformin and the nine arms in which vildagliptin was used in monotherapy (Figure 1). The mean decrease in $\mathrm{HbA}_{1 \mathrm{c}}$ was $0.88 \%$, body weight change was $0.165 \mathrm{~kg}$, and the frequency of hypoglycemia was $1.4 \%$ (Figure 2).

There were 18 RCTs testing sitagliptin, with 3,646 subjects. The meta-analysis showed that $37 \%$ of subjects achieved the $\mathrm{HbA}_{1 \mathrm{c}}$ goal of $<7 \%$ at the end of treatment, without differences between the eight arms in which sitagliptin was added to metformin and the seven arms in which sitagliptin was used in monotherapy (Figure 1). The mean decrease in $\mathrm{HbA}_{1 \mathrm{c}}$ was $0.71 \%$, body weight change was $-0.254 \mathrm{~kg}$, and the frequency of hypoglycemia was $3.1 \%$ (Figure 2).

There were nine RCTs testing saxagliptin, with 1,608 subjects. The meta-analysis showed that $38 \%$ of subjects achieved the $\mathrm{HbA}_{1 \mathrm{c}}$ goal of $<7 \%$ at the end of treatment, without differences between the six arms in which saxagliptin was used at the $5 \mathrm{mg}$ dose, and the three arms in which it was used at the $10 \mathrm{mg}$ dose (Figure 1). The mean decrease in $\mathrm{HbA}_{1 \mathrm{c}}$ was $0.8 \%$, body weight change was $-0.20 \mathrm{~kg}$, and the frequency of hypoglycemia was $3.4 \%$ (Figure 2).

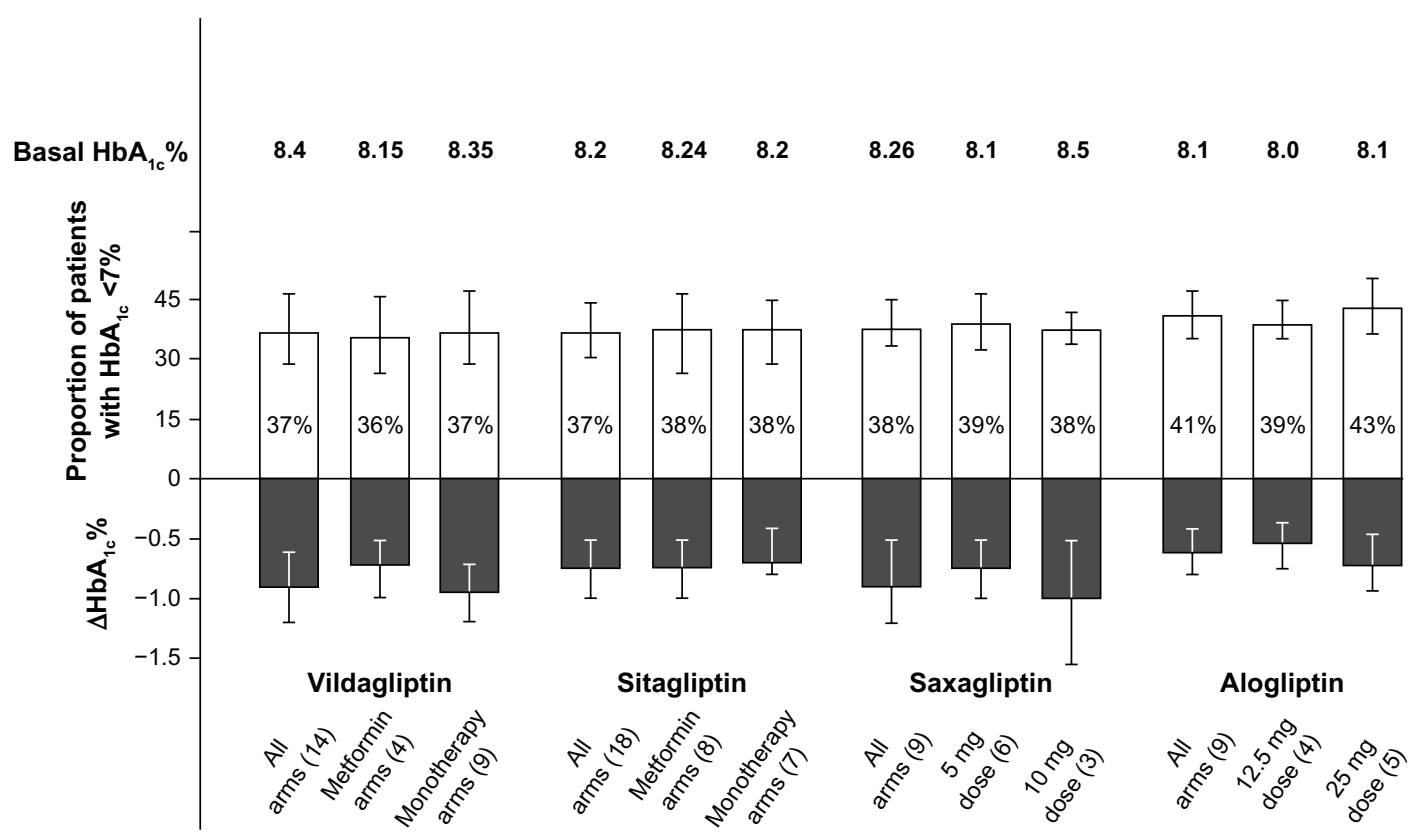

Figure I Proportion of patients with $\mathrm{HbA}_{\mathrm{Ic}}<7 \%$, and absolute decrease of $\mathrm{Hb} \mathrm{A}_{\mathrm{lc}}$ from baseline at endpoint in patients with type 2 diabetes on gliptins after failure of previous treatments.

Note: Basal $\mathrm{HbA}_{\mathrm{lc}}$ represents the mean baseline $\mathrm{HbA}_{\mathrm{lc}}$ level at randomization. 

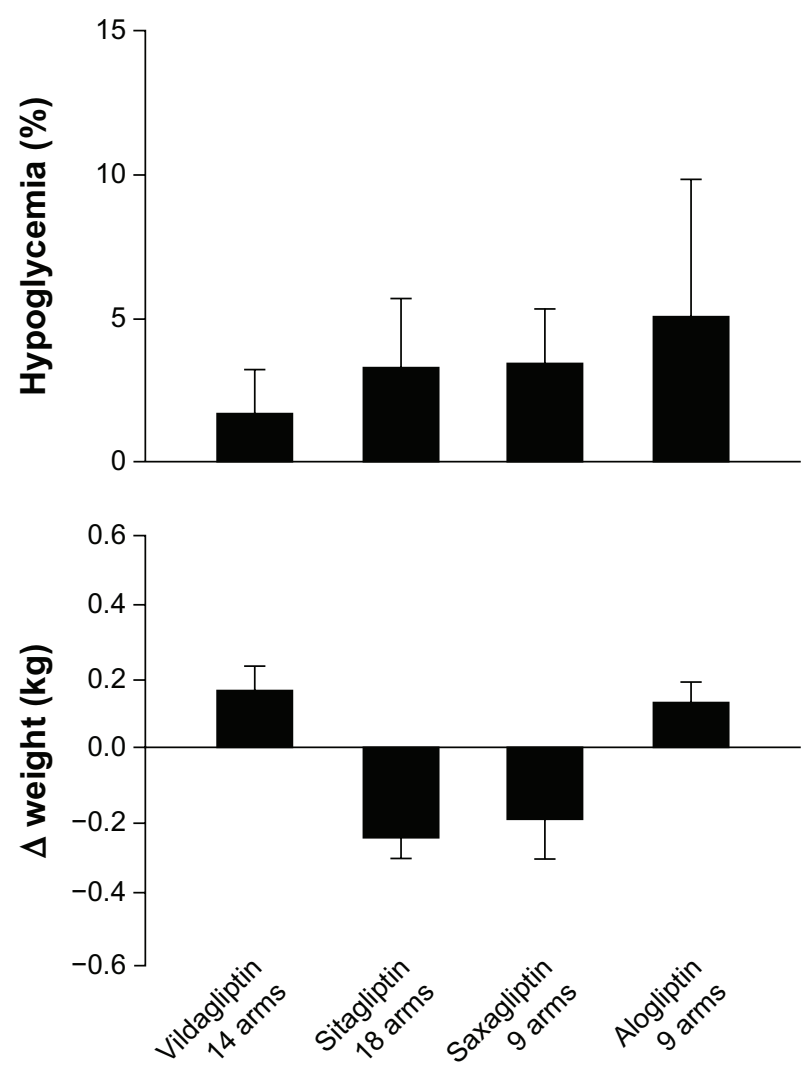

Figure 2 Proportion of patients with hypoglycemia (\%) and changes in weight (kg) in patients with type 2 diabetes on gliptins after failure of previous treatments.

There are few studies comparing DPP-4 inhibitors. There are no head-to-head studies reported comparing sitagliptin and vildagliptin, nor have there been studies comparing alogliptin with these currently approved DPP-4 inhibitors. Caution must therefore be exercised in judging relative efficacy. There is one head-to-head study showing no difference in the effect of saxagliptin combined with metformin as compared with sitagliptin plus metformin. ${ }^{37}$ The improvements in $\mathrm{HbA}_{1 \mathrm{c}}$ seen with alogliptin seem to be in the same range as those seen with other DPP-4 inhibitors. ${ }^{36}$

\section{Focus on alogliptin}

In the pivotal, 26-week, Phase III monotherapy trial ${ }^{38}$ in drug-naïve type 2 diabetic patients inadequately controlled with diet and exercise, alogliptin treatment resulted in significantly greater improvements in glycemic control than placebo, in terms of changes from baseline in $\mathrm{HbA}_{1 \mathrm{c}}$ and fasting glucose levels, and achievement of prespecified target levels of $\mathrm{HbA}_{1 \mathrm{c}}\left(\mathrm{HbA}_{1 \mathrm{c}}<6.5 \%\right.$ or $\left.7 \%\right)$. Moreover, fewer alogliptin (12.5 and $25 \mathrm{mg}$ /day groups) than placebo recipients required hyperglycemic rescue. There were no statistically or clinically meaningful changes in body weight in both alogliptin groups versus the placebo group. There were also significant $(P<0.006)$ improvements in total cholesterol levels in the alogliptin groups after 26 weeks of treatment, but no difference in HDL-cholesterol, LDL-cholesterol, or triglyceride levels.

Alogliptin plus metformin, ${ }^{39}$ pioglitazone, ${ }^{40}$ glibenclamide, ${ }^{41}$ voglibose,${ }^{42}$ or insulin ${ }^{43}$ therapy significantly improved glycemic control compared with placebo in adult patients with inadequately controlled type 2 diabetes. After 26 weeks, changes from baseline in $\mathrm{HbA}_{1 \mathrm{c}}$ levels, which were apparent from week 4 onwards, were all significantly greater in the alogliptin $12.5 \mathrm{mg}$ group (range $-0.4 \%$ to $-0.7 \%$ ) and $25 \mathrm{mg}$ group (range $-0.5 \%$ to $-0.8 \%$ ) than in placebo recipients (range $-0.2 \%$ to $+0.01 \%$ ). Consistent with these findings, significantly more patients in the alogliptin groups than in the placebo groups achieved $\mathrm{HbA}_{1 \mathrm{c}}$ target levels $\left(\mathrm{HbA}_{1 \mathrm{c}}<6.5 \%\right.$ or $\left.<7.0 \%\right)$.

The efficacy of alogliptin in elderly patients with inadequately controlled diabetes has been evaluated in a pooled analysis. ${ }^{44}$ The elderly people (aged $\geq 65$ years; $n=455$ ) were compared to younger people (aged <65 years; $n=1911$ ). There were no statistically significant differences between the two age groups in terms of improvements in glycemic control $\left(\mathrm{HbA}_{1 \mathrm{c}}\right.$ or fasting blood glucose decrease from baseline), irrespective of whether patients had a baseline $\mathrm{HbA}_{1 \mathrm{c}}$ level of $\leq 8 \%$ or $>8 \%$. In addition, $37 \%$ of younger patients achieved an $\mathrm{HbA}_{1 \mathrm{c}}$ level of $\leq 7 \%$ at week 26 (both alogliptin doses). In elderly patients, this target $\mathrm{HbA}_{1 \mathrm{c}}$ level was achieved by $45 \%$ of patients on both alogliptin doses. There were no significant differences between treatment groups or between younger and elderly patients in terms of body weight changes from baseline, or lipid parameters. Table 4 shows the characteristics of the studies ${ }^{38-42,45-51}$ hitherto published evaluating the efficacy and tolerability of alogliptin at different doses in type 2 diabetic patients not adequately controlled on previous treatments.

\section{The EXAMINE trial}

As a result of concerns regarding the association of antidiabetic agents with adverse $\mathrm{CV}$ outcomes, ${ }^{52}$ the FDA released a guidance in December 2008 titled, 'Diabetes Mellitus Evaluating Cardiovascular Risk in New Antidiabetic Therapies to Treat Type 2 Diabetes'. ${ }^{53}$ This guidance outlines requirements for $\mathrm{CV}$ safety assessment before and after approval of all new antidiabetic therapies. Specifically, sponsors must rule out an upper 95\% confidence interval (CI) of the hazard ratio (HR) of 1.8 before approval and 1.3 after approval. Alogliptin has been studied in 3,489 diabetic patients and 1,213 patients on placebo in seven 26-week 


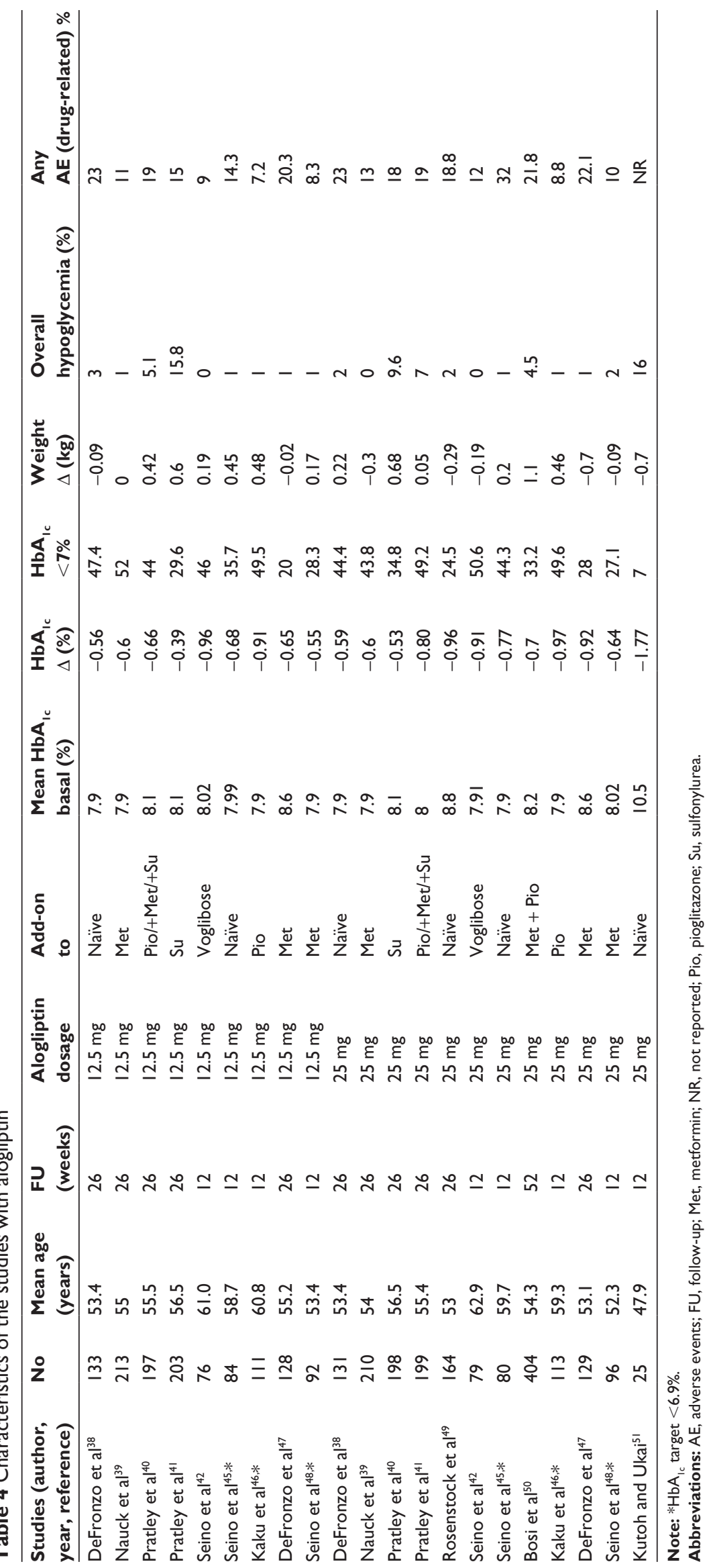


studies and one 12-week study (Phase III studies). Compared with placebo, treatment with alogliptin was associated with a reduced risk (HR: 0.61, 95\% CI: 0.24-1.56) of adjudicated major adverse $\mathrm{CV}$ events (MACE), defined as death from $\mathrm{CV}$ disease, nonfatal myocardial infarction, or nonfatal stroke. ${ }^{54}$ However, the CV event rate was too low to rule out a concern in patients with higher baseline risk.

EXamination of cArdiovascular outcoMes with alogliptIN versus standard of carE (EXAMINE) ${ }^{55}$ is a Phase III, multicenter, prospective, double-blind randomized trial in which alogliptin is being compared with placebo on CV outcomes in approximately 5,400 patients with type 2 diabetes and a well-defined acute coronary syndrome event (myocardial infarction or hospitalization with unstable angina). The primary objective of EXAMINE is to demonstrate the noninferiority of MACE on alogliptin versus placebo in the treatment of type 2 diabetes in a high-risk CV patient group. The study consists of a screening period of up to 2 weeks and a follow-up period of 4.75 years. The length of the study participation will vary but is estimated to be a median of 2 years of study drug treatment. The statistical plan for the trial uses a design that evaluates the HR of alogliptin to placebo first based on the primary $\mathrm{CV}$ composite end-point after accrual of 80-150 primary $\mathrm{CV}$ events and again when there are 550-650 primary CV events. Long-term CV safety of alogliptin is being established using an analytical approach that has both an interim and final assessment. In the first series of analyses, the upper boundary of a group-sequential 1-sided repeated $\mathrm{CI}$ for the HR must be $\leq 1.8$ for registration in the USA. At the end of the study, the upper boundary of a subsequent group-sequential 1-sided repeated CI for the HR must be $\leq 1.3$.

\section{Safety and tolerability}

In clinical studies, DPP-4 inhibitors were generally safe and well-tolerated. ${ }^{56}$ However, there is limited data on their tolerability, in particular on onset of rare events, due to their relatively recent marketing approval. As a drug class, the DPP-4 inhibitors have become accepted in clinical practice due to their excellent tolerability profile, with a low risk of hypoglycemia, a neutral effect on body weight, and once-daily dosing. ${ }^{57}$

In many clinical studies, the most common adverse events (AEs) with incretin therapy were gastrointestinal events, such as vomiting and diarrhea, which generally diminish over time or with a dose-escalation strategy. ${ }^{28,56}$ Nausea, which is the most common AE observed with GLP-1 receptor agonist therapy, is not frequently observed in treatment with DPP-4 inhibitors. ${ }^{56}$ Moreover, both GLP-1 agonists and metformin were associated with a higher discontinuation rate than DPP-4 inhibitors, which is probably related to their higher incidence of gastrointestinal reactions (diarrhea, nausea, and vomiting).$^{58}$ So far, no characteristic pattern of adverse events has been associated with the DPP-4 inhibitors despite the large number of potential substrates for DPP-4. ${ }^{17,28}$ DPP-4 inhibitors are less associated with several specific AEs of traditional antidiabetic treatments. ${ }^{26}$ The neutral effect on body weight of DPP-4 inhibitors can be useful in overweight or obese patients with type 2 diabetes, while the low risk of hypoglycemia may be an advantage in the elderly. ${ }^{25}$ Hypoglycemic events are mainly observed when DPP-4 inhibitors are associated with sulfonylureas (in $20 \%$ of the patients treated in combination) than without sulfonylureas. ${ }^{25,28}$

In clinical trials, other AEs commonly correlated to DPP-4 inhibitors are of mild severity and include nasopharyngitis, headache, and urinary tract infections (UTIs). ${ }^{59-61}$ Another meta-analysis failed to find differences in the incidence of nasopharyngitis, upper respiratory tract infections (URTIs), and UTIs between DPP-4 inhibitors and the other hypoglycemic drugs. ${ }^{58}$ The biological plausibility of the risk associated with this class of drugs may be related to the important role DPP-4 plays in the immune system, being a T-cell co-stimulator. ${ }^{26,62}$ In post-marketing, new AEs have been reported, including hypersensitivity reactions (angioedema, skin toxicity such as Stevens-Johnson syndrome), ${ }^{26,63}$ and also increased rates of infections. ${ }^{59}$ In a nested case-control study conducted using VigiBase, the World Health Organization's Adverse Drug Reactions database, the spontaneous reporting of infections (primarily URTIs) was higher for patients using DPP-4 inhibitors (sitagliptin, vildagliptin, and saxagliptin) compared with users of other antidiabetic drugs (in particular metformin). ${ }^{64}$ Regarding the newer gliptins (alogliptin and linagliptin), close postmarketing vigilance is required because of a limited exposure to these agents at this time. ${ }^{31}$

Although a rare event, pancreatitis has been reported in sitagliptin- and exenatide-treated patients. ${ }^{34}$ However, patients with type 2 diabetes have a near three-fold baseline risk of suffering from acute pancreatitis. ${ }^{65}$ In particular, in 2006, the US FDA received 88 reports of acute pancreatitis in patients who received sitagliptin treatment (as monotherapy or in combination with metformin), including two cases of fatal hemorrhagic or necrotizing pancreatitis, and serious nonfatal cases. ${ }^{66}$ Besides these reports, six patients with hemorrhagic or necrotizing pancreatitis treated with exenatide required hospitalization, and two of them died. ${ }^{67}$ The attention on this concern is still strong. As emphasized 
on the FDA website, ${ }^{68}$ a recent population-based, case-control study, conducted on a large administrative database in the US from 2005 to 2008, and including 1,269 hospitalized cases with acute pancreatitis, showed that treatment with incretinbased therapy (sitagliptin and exenatide) is associated with a doubled risk of developing acute pancreatitis in comparison with nonusers. ${ }^{69}$

A previous study has examined the FDA adverse event reporting system (AERS) database, and has noted a 6-fold risk for pancreatitis with the use of sitagliptin or exenatide as compared with other therapies. Moreover, this analysis showed the reported event rate for pancreatic cancer was 2.9-fold greater in patients treated with sitagliptin and exenatide compared with other therapies. Unlike patients treated with GLP-1 agonists (in particular liraglutide), the reported event rate for thyroid cancer did not reach statistical significance in sitagliptin-treated patients. These observations have been explained as being due to incomplete data and reporting bias in the FDA database. ${ }^{70}$ In preclinical toxicology studies, GLP-1 activation promoted the development of C-cell hyperplasia and medullary thyroid cancer, while this action on human C-cells is uncertain. ${ }^{71}$ In addition, there is evidence in animal models that DPP-4 inhibition is related to melanoma, prostate cancer, ovarian cancer neuroblastoma, and lung cancer. In malignancy, low levels of DPP-4 seems to be associated with dissemination or metastasis. ${ }^{72}$ Immunomodulatory effects of DPP-4 inhibition might explain the increased risk for all cancers. ${ }^{72}$ Examination of pancreata from agematched organ donors with type 2 diabetes (DM) treated by incretin therapy resulted in a marked expansion of the exocrine and endocrine pancreatic compartments, with increased proliferation and dysplasia, and $\alpha$-cell hyperplasia. $^{73}$ Therefore, careful long-term surveillance on the safety profile of DPP-4 inhibitors is mandatory. ${ }^{74}$

Diabetic patients are at increased risk of $\mathrm{CV}$ disease. Rosiglitazone was been withdrawn from the market in the European Union (EU) in $2010,{ }^{75}$ because of a possible increased risk of ischemic heart disease associated with its use. $^{76}$ Several preclinical ${ }^{77}$ and clinical studies have suggested a possible beneficial effect on CV risk associated with DPP-4 inhibitors, which also seem to possess a direct effect on the heart, independent of the incretin system. ${ }^{78}$ They may exert some favorable effects on risk factors, resulting in a reduction of blood pressure, an improvement of postprandial lipid levels, and a reduction of high-sensitivity C-reactive protein (hsCRP). ${ }^{25,78}$ The endothelial dysfunction is also improved by gliptins. ${ }^{79}$ Several large randomized Phase III trials are ongoing and will increase our knowledge about the effect on $\mathrm{CV}$ outcomes and safety. ${ }^{80-83}$

\section{Focus on alogliptin}

Overall, the tolerability profile of alogliptin, used alone or in association with other antidiabetic agents, did not differ from that of placebo. Severe hypoglycemia has never been reported; however, skin-related adverse events (especially pruritus) were more common in patients treated with alogliptin compared with other treatment groups. ${ }^{84,85}$ Although in preclinical studies, the use of other DPP-4 inhibitors, such as saxagliptin and vildagliptin, have been associated with necrotic skin lesions in monkeys ${ }^{84-86}$ these events have not been observed in clinical trials. In the postmarketing phase, some patients treated with sitagliptin presented Stevens-Johnson syndrome and other exfoliative skin reactions, besides serious allergic reactions and anaphylaxis. ${ }^{87}$

The combination of alogliptin and metformin is well tolerated. Nasopharyngitis was the most commonly reported adverse event in one study, ${ }^{48}$ and the overall incidence of infections was highest among the other adverse events. Alogliptin is also safe when added to pioglitazone in metformin-treated patients. The incidence of skin events was similar among treatment groups, while the incidence of infections was slightly greater in patients treated with alogliptin $25 \mathrm{mg}$ plus pioglitazone than pioglitazone alone or with alogliptin $12.5 \mathrm{mg} .{ }^{47} \mathrm{Kaku}$ et $\mathrm{al}^{46}$ observed that nasopharyngitis, even if of mild severity, was the most commonly reported adverse event when alogliptin was added to pioglitazone in naïve patients. The combination of alogliptin $(25 \mathrm{mg})$ and pioglitazone induced edema-related events (incidence $\geq 3 \%$ ), which were not observed with a lower dosage of alogliptin. ${ }^{46}$ The safety profile of the combination alogliptin and sulfonylurea is also favorable, without an increased incidence of hypoglycemia, as compared with placebo. ${ }^{41}$ Finally, alogliptin added to insulin also shows an acceptable tolerability profile, characterized by gastrointestinal, skin, and infection-related events, without increasing weight gain and the incidence of hypoglycemia. ${ }^{43}$ The frequency of hypoglycemia with alogliptin reported in Figure 2 is that obtained from four studies; ${ }^{38-41}$ in two of these studies, ${ }^{40,41}$ alogliptin was added to a previous sulfonylurea treatment, which was associated with higher prevalence of hypoglycemia, which is not different from placebo. The analysis of data from Table 4 shows that the overall frequency of hypoglycemia is 3.57 (mean, where SD: 4.76) or 1.0 (median, where interquartile range: $1.0-4.6)$. 
No clinically meaningful changes in laboratory test results have been reported. ${ }^{39,43,46}$ Moreover, few patients died, but the fatal events were not considered to be related to study medication. ${ }^{39,46,47}$ In the study of Nauck et al, ${ }^{39}$ two patients in the alogliptin $(25 \mathrm{mg})+$ metformin group reported severe pulmonary embolism and congestive heart failure, which were considered 'possibly related' to the study drug. On the other hand, alogliptin seems to have anti-atherosclerotic effects, including decreasing cholesterol and low density lipoproteins ${ }^{88}$ both alone and in association with pioglitazone, with a potential reduction of $\mathrm{CV}$ risk in patients with type 2 diabetes..$^{55,88}$ Moreover, a pool analysis of six studies showed that the tolerability of alogliptin was similar in younger and elderly patients. ${ }^{44}$

\section{Patient-focused perspectives}

Unlike incretin mimetics, which need subcutaneous injections, DPP-4 inhibitors are administrated by oral ingestion. The different route of administration could influence patients' compliance, leading to possible increased adherence to therapy in patients treated with DPP-4 inhibitors. However, some evidence suggests higher patient satisfaction with GLP-1 analogs than gliptins ${ }^{89,90} \mathrm{~A}$ review on patient-reported outcomes of incretin-based therapies showed that patients' satisfaction when treated with GLP-1 receptor agonists was greater in comparison with DPP-4 inhibitors, probably due to greater efficacy and weight loss. ${ }^{90}$ Patients' perception of hypoglycemic condition was similar between the two groups. In a study comparing exenatide and sitagliptin, both groups experienced significant improvements on psychological well-being, although exenatide improved patients' satisfaction more than sitagliptin. ${ }^{91}$ Moreover, weight-related quality of life also improved in patients treated with incretin-based therapies. ${ }^{90}$ Overall, patients were highly satisfied with an incretin-based treatment compared with traditional antidiabetic treatments.

\section{Place in therapy}

The recent Position Statement of the American Diabetes Association and the European Association for the Study of Diabetes states that metformin, if not contraindicated and if tolerated, is the preferred and most cost-effective first agent. ${ }^{4}$ If metformin cannot be used, another oral agent could be chosen, such as a sulfonylurea/glinide, pioglitazone, or a DPP-4 inhibitor. With a distinct paucity of long-term comparative-effectiveness trials available, uniform recommendations on the best agent to be combined with metformin cannot be made. ${ }^{11}$ Thus, the advantages and disadvantages of specific drugs for each patient should be considered.
The DPP-4 inhibitors represent a highly promising, novel class of oral agents for the treatment of type 2 diabetes. Their novelty lies in their dual action on $\alpha$ - and $\beta$-cell function, leading to an improved profile of glucagon and insulin secretion patterns after meal. These drugs are weight-neutral, do not provoke hypoglycemia, and are not associated with gastrointestinal adverse events. Long-term clinical trial data are not yet available to assess the sustainability of glycemic control and protection of $\beta$-cell mass. The interference of the DPP-4 inhibitors with immune function is poorly understood and warrants further research. Another potential disadvantage is a higher cost per day of clinical use as compared to insulin, metformin, or pioglitazone, which is an economic drawback for the DPP-4 inhibitors. ${ }^{92}$

Like other DPP-4 inhibitors, alogliptin is a novel, and hence, costly agent of modest to moderate efficacy. Even then, the DPP-4 inhibitors have found a place in the treatment of vulnerable elderly patients because of minimal risk of hypoglycemia and lack of significant drug-drug interactions. Its primary use will presumably be as an adjunct to other hypoglycemic agents rather than as a first-line agent, although its primary use can be foreseen for patients who are metformin intolerant or in those with renal insufficiency where metformin is contraindicated. Alogliptin will be used most in patients in whom it is especially important to avoid hypoglycemic events: in patients with congestive heart failure, renal failure, and liver disease, hypoglycemia can be more severe and refractory to treatment. In the elderly, hypoglycemic events increase the risk of injurious falls as well as coronary events. Alogliptin and other DPP-4 inhibitors could potentially replace the sulfonylureas in such vulnerable patients. Moreover, due to the paucity of head-to-head clinical data between DDP-4 inhibitors, ${ }^{93}$ indirect comparisons assessing their efficacy or safety do not allow us to establish if one agent is superior to another within the class. Longer duration studies with careful post-approval surveillance are needed to assess the safety of alogliptin. Such large-scale, longduration studies not only will characterize the long-term safety of alogliptin but should also shed light on possible $\beta$-cell preservation.

\section{Disclosure}

The authors report no conflicts of interest in this work.

\section{References}

1. Whiting DR, Guariguata L, Weil C, Shaw J. IDF Diabetes Atlas: global estimates of the prevalence of diabetes for 2011 and 2030. Diabetes Res Clin Pract. 2011;94(3):311-321. 
2. Go AS, Mozaffarian D, Roger VL, et al; American Heart Association Statistics Committee and Stroke Statistics Subcommittee. Heart disease and stroke statistics - 2013 update: a report from the American Heart Association. Circulation. 2013;127(1):e6-e245 Page 13.

3. American Diabetes Association. Position Statement. Standards of medical care in diabetes - 2013. Diabetes Care. 2013;36(Suppl 1):S11-S66.

4. Inzucchi SE, Bergenstal RM, Buse JB, et al; American Diabetes Association (ADA); European Association for the Study of Diabetes (EASD). Management of hyperglycemia in type 2 diabetes: a patient-centered approach: position statement of the American Diabetes Association (ADA) and the European Association for the Study of Diabetes (EASD). Diabetes Care. 2012;35(6):1364-1379.

5. Selvin E, Bolen S, Yeh HC, et al. Cardiovascular outcomes in trials of oral diabetes medications. Arch Intern Med. 2008;168(19):2070-2080.

6. Esposito K, Bellastella G, Giugliano D. When metformin fails in type 2 diabetes mellitus. Arch Intern Med. 2011;171(4):365-366.

7. Giugliano D, Ceriello A, Esposito K. $\mathrm{HbA}_{1 \mathrm{c}}$ targets for type 2 diabetes: How many, ...how far! Diabetes Res Clin Pract. 2012;96(3): 414-415.

8. Colagiuri S. Optimal management of type 2 diabetes: the evidence. Diabetes Obes Metab. 2012;14(Suppl 1):3-8.

9. Esposito K, Chiodini P, Capuano A, Petrizzo M, Improta MR, Giugliano D. Basal supplementation of insulin lispro protamine suspension versus insulin glargine and detemir for type 2 diabetes: metaanalysis of randomized controlled trials. Diabetes Care. 2012;35(12): 2698-2705.

10. Giugliano D, Esposito K. Clinical inertia as a clinical safeguard. JAMA. 2011;305(15):1591-1592.

11. Esposito K, Ceriello A, Giugliano D. Does personalized diabetology overcome clinical uncertainty and therapeutic inertia in type 2 diabetes? Endocrine. Epub March 12, 2013.

12. Gutniak M, Ørskov C, Holst JJ, Ahrén B, Efendic S. Antidiabetic effect of glucagon-like peptide-1 (7-36) amide in normal subjects and patients with diabetes mellitus. N Engl J Med. 1992;326(20):1316-1322.

13. Elrick H, Stimmler L, Hlad CJ Jr, Arai Y. Plasma insulin response to oral and intravenous glucose administration. J Clin Endocrinol Metab. 1964;24(10):1076-1082.

14. Creutzfeldt W. The incretin concept today. Diabetologia. 1979;16(2): 75-85.

15. Baggio LL, Drucker DJ. Biology of incretins: GLP-1 and GIP Gastroenterology. 2007;132(6):2131-2157.

16. Doyle ME, Egan JM. Mechanisms of action of glucagon-like peptide 1 in the pancreas. Pharmacol Ther. 2007;113(3):549-593.

17. Drucker DJ, Nauck MA. The incretin system: glucagon-like peptide-1 receptor agonists and dipeptidyl peptidase-4 inhibitors in type 2 diabetes. Lancet. 2006;368(9548):1696-1705.

18. Nauck MA. Incretin-based therapies for type 2 diabetes mellitus: properties, functions, and clinical implications. Am J Med. 2011;124(Suppl 1): S3-S18.

19. Baetta R, Corsini A. Pharmacology of dipeptidyl peptidase-4 inhibitors: similarities and differences. Drugs. 2011;71(11):1441-1467.

20. Dhillon S. Sitagliptin: a review of its use in the management of type 2 diabetes mellitus. Drugs. 2010;70(4):489-512.

21. Keating GM. Vildagliptin: a review of its use in type 2 diabetes mellitus. Drugs. 2010;70(16):2089-2112.

22. Neumiller JJ, Campbell RK. Saxagliptin: a dipeptidyl peptidase-4 inhibitor for the treatment of type 2 diabetes mellitus. Am J Health Syst Pharm. 2010;67(18):1515-1525.

23. Scott LJ. Alogliptin: a review of its use in the management of type 2 diabetes mellitus. Drugs. 2010;70(15):2051-2072.

24. Scott LJ. Linagliptin: in type 2 diabetes mellitus. Drugs. 2011;71(5): 611-624

25. Scheen AJ. A review of gliptins in 2011. Expert Opin Pharmacother. 2012;13(1):81-99.

26. Verspohl EJ. Novel therapeutics for type 2 diabetes: incretin hormone mimetics (glucagon-like peptide-1 receptor agonists) and dipeptidyl peptidase-4 inhibitors. Pharmacol Ther. 2009;124(1):113-138.
27. Thomas L, Eckhardt M, Langkopf E, Tadayyon M, Himmelsbach F, Mark M. (R)-8-(3-amino-piperidin-1-yl)-7-but-2-ynyl-3-methyl1-(4-methyl-quinazolin-2-ylm ethyl)-3,7-dihydro-purine-2,6-dione (BI 1356), a novel xanthine-based dipeptidyl peptidase 4 inhibitor, has a superior potency and longer duration of action compared with other dipeptidyl peptidase-4 inhibitors. J Pharmacol Exp Ther. 2008;325(1): $175-182$.

28. Gallwitz B. Emerging DPP-4 inhibitors: focus on linagliptin for type 2 diabetes. Diabetes Metab Syndr Obes. 2013;6:1-9.

29. Gupta V, Kalra S. Choosing a gliptin. Indian J Endocrinol Metab. 2011;15(4):298-308.

30. Golightly LK, Drayna CC, McDermott MT. Comparative clinical pharmacokinetics of dipeptidyl peptidase-4 inhibitors. Clin Pharmacokinet. 2012;51(8):501-514. Erratum in Clin Pharmacokinet. 2012;51(12):831.

31. Richard KR, Shelburne JS, Kirk JK. Tolerability of dipeptidyl peptidase-4 inhibitors: a review. Clin Ther. 2011;33(11):1609-1629.

32. Scheen AJ. Pharmacokinetics of dipeptidylpeptidase-4 inhibitors. Diabetes Obes Metab. 2010;12(8):648-658.

33. Kania DS, Gonzalvo JD, Weber ZA. Saxagliptin: a clinical review in the treatment of type 2 diabetes mellitus. Clin Ther. 2011;33(8): 1005-1022.

34. Brown DX, Evans M. Choosing between GLP-1 receptor agonists and DPP-4 inhibitors: a pharmacological perspective. J Nutr Metab. 2012;2012:381713.

35. Scheen AJ. Dipeptidylpeptidase-4 inhibitors (gliptins): focus on drug-drug interactions. Clin Pharmacokinet. 2010;49(9):573-588.

36. Esposito K, Cozzolino D, Bellastella G, et al. Dipeptidyl peptidase-4 inhibitors and $\mathrm{HbA}_{1 \mathrm{c}}$ target of $<7 \%$ in type 2 diabetes: meta-analysis of randomized controlled trials. Diabetes Obes Metab. 2011;13(7):594-603.

37. Scheen AJ, Charpentier G, Ostgren CJ, Hellqvist A, Gause-Nilsson I. Efficacy and safety of saxagliptin in combination with metformin compared with sitagliptin in combination with metformin in adult patients with type 2 diabetes mellitus. Diabetes Metab Res Rev. 2010;26(7): 540-549.

38. DeFronzo RA, Fleck PR, Wilson CA, Mekki Q; Alogliptin Study 010 Group. Efficacy and safety of the dipeptidyl peptidase-4 inhibitor alogliptin in patients with type 2 diabetes and inadequate glycemic control: a randomized, double-blind, placebo-controlled study. Diabetes Care. 2008;31(12):2315-2317.

39. Nauck MA, Ellis GC, Fleck PR, Wilson CA, Mekki Q; Alogliptin Study 008 Group. Efficacy and safety of adding the dipeptidyl peptidase-4 inhibitor alogliptin to metformin therapy in patients with type 2 diabetes inadequately controlled with metformin monotherapy: a multicentre, randomised, double-blind, placebo-controlled study. Int J Clin Pract. 2009;63(1):46-55.

40. Pratley RE, Reusch JE, Fleck PR, Wilson CA, Mekki Q; Alogliptin Study 009 Group. Efficacy and safety of the dipeptidyl peptidase-4 inhibitor alogliptin added to pioglitazone in patients with type 2 diabetes: a randomized, double-blind, placebo-controlled study. Curr Med Res Opin. 2009;25(10):2361-2371.

41. Pratley RE, KipnesMS, Fleck PR, Wilson C, Mekki Q; Alogliptin Study 007 Group. Efficacy and safety of the dipeptidyl peptidase-4 inhibitor alogliptin in patients with type 2 diabetes inadequately controlled by glyburide monotherapy. Diabetes Obes Metab. 2009;11(2):167-176.

42. Seino Y, Fujita T, Hiroi S, Hirayama M, Kaku K. Alogliptin plus voglibose in Japanese patients with type 2 diabetes: a randomized, double-blind, placebo-controlled trial with an open-label, long-term extension. Curr Med Res Opin. 2011,27(Suppl 3):21-29.

43. Rosenstock J, Rendell MS, Gross JL, Fleck PR, Wilson CA, Mekki Q. Alogliptin added to insulin therapy in patients with type 2 diabetes reduces $\mathrm{HbA}_{1 \mathrm{c}}$ without causing weight gain or increased hypoglycaemia. Diabetes Obes Metab. 2009;11(12):1145-1152.

44. Pratley RE, McCall T, Fleck PR, Wilson CA, Mekki Q. Alogliptin use in elderly people: a pooled analysis from phase 2 and 3 studies. $J \mathrm{Am}$ Geriatr Soc. 2009;57(11):2011-2019. 
45. Seino Y, Fujita T, Hiroi S, Hirayama M, Kaku K. Efficacy and safety of alogliptin in Japanese patients with type 2 diabetes mellitus: a randomized, double-blind, dose-ranging comparison with placebo, followed by a long-term extension study. Curr Med Res Opin. 2011;27(9): 1781-1792.

46. Kaku K, Itayasu T, Hiroi S, Hirayama M, Seino Y. Efficacy and safety of alogliptin added to pioglitazone in Japanese patients with type 2 diabetes: a randomized, double-blind, placebo-controlled trial with an open-label long-term extension study. Diabetes Obes Metab. 2011;13(11):1028-1035.

47. DeFronzo RA, Burant CF, Fleck P, Wilson C, Mekki Q, Pratley RE. Efficacy and tolerability of the DPP-4 inhibitor alogliptin combined with pioglitazone, in metformin-treated patients with type 2 diabetes. J Clin Endocrinol Metab. 2012;97(5):1615-1622.

48. Seino Y, Miyata Y, Hiroi S, Hirayama M, Kaku K. Efficacy and safety of alogliptin added to metformin in Japanese patients with type 2 diabetes: a randomized, double-blind, placebo-controlled trial with an open-label, long-term extension study. Diabetes Obes Metab. 2012;14(10):927-936.

49. Rosenstock J, Inzucchi SE, Seufert J, Fleck PR, Wilson GA, Mekki Q. Initial combination therapy with alogliptin and pioglitazone in drugnaïve patients with type 2 diabetes. Diabetes Care. 2010;33(11): 2406-2408.

50. Bosi E, Ellis GC, Wilson CA, Fleck PR. Alogliptin as a third oral antidiabetic drug in patients with type 2 diabetes and inadequate glycaemic control on metformin and pioglitazone: a 52-week, randomized, doubleblind, active-controlled, parallel-group study. Diabetes Obes Metab. 2011;13(12):1088-1096.

51. Kutoh E, Ukai Y. Alogliptin as an initial therapy in patients with newly diagnosed, drug nave type 2 diabetes: a randomized, control trial. Endocrine. 2012;41(3):435-441.

52. Goldfine AB. Assessing the cardiovascular safety of diabetes therapies. N Engl J Med. 2008;359(11):1092-1095.

53. US Food and Drug Administration. FDA announces new recommendations on evaluating cardiovascular risk in drugs intended to treat type 2 diabetes [press release]. Silver Springs, MD: US Food and Drug Administration; 2008 [December 17]. Available from: http://www.fda. gov/NewsEvents/Newsroom/PressAnnouncements/2008/ucm116994. htm. Accessed April 29, 2013.

54. White WB, Pratley R, Fleck P, et al. Cardiovascular safety of the dipetidyl peptidase-4 inhibitor alogliptin in type 2 diabetes mellitus. Diabetes Obes Metab. 2013;15(7):668-673.

55. White WB, Bakris GL, Bergenstal RM, et al. EXamination of CArdiovascular OutcoMes with AlogliptIN versus Standard of CarE in Patients with Type 2 Diabetes Mellitus and Acute Coronary Syndrome (EXAMINE): a cardiovascular safety study of the dipeptidyl peptidase 4 inhibitor alogliptin in patients with type 2 diabetes with acute coronary syndrome. Am Heart J. 2011;162(4):620-626.e1.

56. Neumiller JJ, Wood L, Campbell RK. Dipeptidyl peptidase-4 inhibitors for the treatment of type 2 diabetes mellitus. Pharmacotherapy. 2010;30(5):463-484.

57. Karagiannis T, Paschos P, Paletas K, Matthews DR, Tsapas A. Dipeptidyl peptidase- 4 inhibitors for treatment of type 2 diabetes mellitus in the clinical setting: systematic review and meta-analysis. $B M J$. 2012;344:e1369.

58. Mikhail N. Safety of dipeptidyl peptidase 4 inhibitors for treatment of type 2 diabetes. Curr Drug Saf. 2011;6(5):304-309.

59. Amori RE, Lau J, Pittas AG. Efficacy and safety of incretin therapy in type 2 diabetes: systematic review and meta-analysis. JAMA. 2007;298(2):194-206.

60. Monami M, Ahrén B, Dicembrini I, Mannucci E. Dipeptidyl peptidase-4 inhibitors and cardiovascular risk: a meta-analysis of randomized clinical trials. Diabetes Obes Metab. 2013;15(2):112-120.

61. Gooßen K, Gräber S. Longer term safety of dipeptidyl peptidase- 4 inhibitors in patients with type 2 diabetes mellitus: systematic review and meta-analysis. Diabetes Obes Metab. 2012;14(12): 1061-1072.
62. Desai S, Brinker A, Swann J, Iyasu S. Sitagliptin-associated drug allergy: review of spontaneous adverse event reports. Arch Intern Med. 2010;170(13):1169-1171

63. Willemen MJ, Mantel-Teeuwisse AK, Straus SM, Meyboom RH, Egberts TC, Leufkens HG. Use of dipeptidyl peptidase-4 inhibitors and the reporting of infections: a disproportionality analysis in the World Health Organization VigiBase. Diabetes Care. 2011;34(2):369-374.

64. Noel RA, Braun DK, Patterson RE, Bloomgren GL. Increased risk of acute pancreatitis and biliary disease observed in patients with type 2 diabetes: a retrospective cohort study. Diabetes Care. 2009;32(5):834-838.

65. US Food and Drug Administration. Information for Healthcare Professionals - Acute pancreatitis and sitagliptin (marketed as Januvia and Janumet). Silver Spring, MD: US Food and Drug Administration; [September 25, 2009]. Available from: http://www.fda.gov/Drugs/ DrugSafety/PostmarketDrugSafetyInformationforPatientsandProviders/DrugSafetyInformationforHeathcareProfessionals/ucm183764.htm. Accessed March 19, 2013.

66. US Food and Drug Administration. Byetta (exenatide); Audience: Endocrinologists, other healthcare professionals, consumers. Silver Spring, MD: US Food and Drug Administration; [updated June 16, 2009; cited May 30, 2011]. Available from: http://www.fda.gov/Safety/ MedWatch/SafetyInformation/SafetyAlertsforHumanMedicalProducts/ ucm079781.htm. Accessed June 18, 2013.

67. US Food and Drug Administration. FDA Drug Safety Communication: FDA investigating reports of possible increased risk of pancreatitis and pre-cancerous findings of the pancreas from incretin mimetic drugs for type 2 diabetes. Silver Spring, MD: US Food and Drug Administration; [March 14, 2013; updated March 18, 2013]. Available from: http://www. fda.gov/Drugs/DrugSafety/ucm343187.htm. Accessed June 18, 2013.

68. Singh S, Chang HY, Richards TM, Weiner JP, Clark JM, Segal JB. Glucagonlike peptide 1-based therapies and risk of hospitalization for acute pancreatitis in type 2 diabetes mellitus: A population-based matched case-control study. JAMA Intern Med. 2013;173(7):534-539.

69. Elashoff M, Matveyenko AV, Gier B, Elashoff R, Butler PC. Pancreatitis, pancreatic, and thyroid cancer with glucagon-like peptide1-based therapies. Gastroenterology. 2011;141(1):150-156.

70. Drucker DJ, Sherman SI, Gorelick FS, Bergenstal RM, Sherwin RS, Buse JB. Incretin-based therapies for the treatment of type 2 diabetes: evaluation of the risks and benefits. Diabetes Care. 2010;33(2):428-433.

71. Garg MK, Kharb S, Pandit A. Prescribing gliptins: enthusiasm should be coupled with caution. Indian J Endocrinol Metab. 2012;16(2):324-325.

72. European Medicines Agency (EMA). EMA recommends suspension of Avandia, Avandamet and Avaglim [press release]. London, UK: European Medicines Agency; [cited May 30, 2011]. Available from: http://www.ema.europa.eu/docs/en_GB/document_library/ Press_release/2010/09/WC500096996.pdf. Accessed June 18, 2013.

73. Butler AE, Campbell-Thompson M, Gurlo T, Dawson DW, Atkinson M, Butler PC. Marked expansion of exocrine and endocrine pancreas with incretin therapy in humans with increased exocrine pancreas dysplasia and the potential for glucagon-producing neuroendocrine tumors. Diabetes. Epub March 22, 2013.

74. Kahn SE. Incretin therapy and islet pathology - A time for caution. Diabetes. Epub April 17, 2013.

75. Nissen SE, Wolski K. Effect of rosiglitazone on the risk of myocardial infarction and death from cardiovascular causes. $N$ Engl J Med. 2007;356(24):2457-2471

76. Bose AK, Mocanu MM, Carr RD, Brand CL, Yellon DM. Glucagon-like peptide 1 can directly protect the heart against ischemia/reperfusion injury. Diabetes. 2005;54(1):146-151.

77. Jose T, Inzucchi SE. Cardiovascular effects of the DPP-4 inhibitors. Diab Vasc Dis Res. 2012;9(2):109-116.

78. Fadini GP, Boscaro E, Albiero M, et al. The oral dipeptidyl peptidase-4 inhibitor sitagliptin increases circulating endothelial progenitor cells in patients with type 2 diabetes: possible role of stromal-derived factor-1alpha. Diabetes Care. 2010;33(7):1607-1609. 
79. Merck. TECOS: Sitagliptin Cardiovascular Outcome Study. In: ClinicalTrials.gov [website on the Internet]. Bethesda, MD: US National Library of Medicine; 2008 [updated August 14, 2012]. Available from: http://clinicaltrials.gov/show/NCT00790205. NLM identifier: NCT00790205. Accessed June 18, 2013.

80. Takeda. EXAMINE: Cardiovascular Outcomes Study of Alogliptin in Subjects With Type 2 Diabetes and Acute Coronary Syndrome. In: ClinicalTrials.gov [website on the Internet]. Bethesda, MD: US National Library of Medicine; 2009 [updated June 11, 2013]. Available from: http:/clinicaltrials.gov/show/NCT00968708. NLM identifier: NCT00968708. Accessed June 18, 2013.

81. AstraZeneca. SAVOR-TIMI 53: Does Saxagliptin Reduce the Risk of Cardiovascular Events when Used Alone or Added to Other Diabetes Medications? In: ClinicalTrials.gov [website on the Internet]. Bethesda, MD: US National Library of Medicine; 2010 [updated November 19, 2012]. Available from: http://clinicaltrials.gov/ct2/show/NCT01107886. NLM identifier: NCT01107886. Accessed June 18, 2013.

82. Boehringer Ingelheim Pharmaceuticals. CAROLINA: Cardiovascular Outcome Study of Linagliptin Versus Glimepiride in Patients with Type 2 Diabetes. In: ClinicalTrials.gov [website on the Internet]. Bethesda, MD: US National Library of Medicine; 2010 [updated June 12, 2013]. Available from: http://clinicaltrials.gov/show/NCT01243424. NLM identifier: NCT01243424. Accessed June 18, 2013.

83. Rendell M, Drincic A, Andukuri R. Alogliptin benzoate for the treatment of type 2 diabetes. Expert Opin Pharmacother. 2012;13(4):553-563.

84. Andukuri R, Drincic A, Rendell M. Alogliptin: a new addition to the class of DPP-4 inhibitors. Diabetes Metab Syndr Obes. 2009;2:117-126.

85. European Medicine Agency. Summary of Product Characteristics of Vildagliptin. London: European Medicine Agency; Available from:http://www.ema.europa.eu/docs/en_GB/document_library/ EPAR_-_Product_Information/human/000771/WC500020327.pdf. Accessed June 18, 2013.
86. US Food and Drug Administration. Janumet (sitagliptin/metformin $\mathrm{HCl}$ ) Tablets Detailed View: Safety Labeling Changes Approved By FDA Center for Drug Evaluation and Research (CDER) - January 2008. Silver Spring, MD: US Food and Drug Administration; [January 2008; updated June 19, 2009]. Available from: http://www.fda.gov/Safety/ MedWatch/SafetyInformation/Safety-RelatedDrugLabelingChanges/ ucm106669.htm. Accessed June 18, 2013.

87. Kapoor S. Potent antiatherosclerotic effects of alogliptin in addition to its potent antidiabetic effects. Diabetes Metab Syndr Obes. 2012;5: $121-123$.

88. Eliasson B, Möller-Goede D, Eeg-Olofsson K, et al. Lowering of postprandial lipids in individuals with type 2 diabetes treated with alogliptin and/or pioglitazone: a randomised double-blind placebo-controlled study. Diabetologia. 2012;55(4):915-925.

89. Russell S. Incretin-based therapies for type 2 diabetes mellitus: a review of direct comparisons of efficacy, safety and patient satisfaction. Int $J$ Clin Pharm. 2013;35(2):159-172.

90. Davies M, Speight J. Patient-reported outcomes in trials of incretinbased therapies in patients with type 2 diabetes mellitus. Diabetes Obes Metab. 2012;14(10):882-892.

91. Best JH, Rubin RR, Peyrot M, et al. Weight-related quality of life, health utility, psychological well-being, and satisfaction with exenatide once weekly compared with sitagliptin or pioglitazone after 26 weeks of treatment. Diabetes Care. 2011;34(2):314-319.

92. Irons BK, Weis JM, Stapleton MR, Edwards KL. An update in incretinbased therapy: a focus on dipeptidyl peptidase -4 inhibitors. Curr Diabetes Rev. 2012;8(3):169-182.

93. Scheen AJ, Charpentier G, Ostgren CJ, Hellqvist A, Gause-Nilsson I. Efficacy and safety of saxagliptin in combination with metformin compared with sitagliptin in combination with metformin in adult patients with type 2 diabetes mellitus. Diabetes Metab Res Rev 2010;26: $540-549$.

\section{Publish your work in this journal}

Drug Design, Development and Therapy is an international, peerreviewed open-access journal that spans the spectrum of drug design and development through to clinical applications. Clinical outcomes, patient safety, and programs for the development and effective, safe, and sustained use of medicines are a feature of the journal, which

\section{Dovepress}

has also been accepted for indexing on PubMed Central. The manuscript management system is completely online and includes a very quick and fair peer-review system, which is all easy to use. Visit http://www.dovepress.com/testimonials.php to read real quotes from published authors. 